\title{
DEVELOPMENT OF A PROFESSIONAL TRAINING COURSE TO ENHANCE PJBL COMPETENCIES OF TEACHERS AT A TECHNICAL UNIVERSITY
}

\author{
Ekaterina Gradaleva \\ Samara State Technical University, Russian Federation \\ Marina Polukhina \\ Samara State Technical University, Russian Federation
}

\begin{abstract}
The research is aimed at designing a professional development course where special emphasis is laid upon teacher preparation for international project activities. A poll has been conducted to find out whether technical university teachers are inclined to using project-based learning $(P J B L)$ in the classroom. It shows that in reality most of them don't have a holistic view of the approach. They mention the lack of a methodological base, language skills and ICT practice to integrate innovative techniques into their teaching. It becomes obvious that there is a need to rethink the design of teacher preparation to cultivate educators who are able to demonstrate PJBL practices and be effective in preparing students for the project-based world. To better understand the ways of orienting teachers toward the project-based approach a set of teacher competencies has been specified. It comprises motivation, personal qualities and models of behavior that help an educator make the transition to new methods of teaching, methodological knowledge, XXI century skills (critical thinking, creativity, collaboration, communication, problem-solving, decision making), transnational communicative competencies (linguistic, rhetoric, cultural, media). These components serve as a basis for the professional development course content. As a result, it is proposed to include three major units for training: PJBL Methodology; Professional English and Intercultural Communication; Information and Communication Technologies.
\end{abstract}

Keywords: PJBL competencies, professional development course, project-based approach, Pyramid of PJBL Teacher Development, XXI century competencies.

\section{Introduction}

Nowadays, higher education has stepped into the era of change leading to the modernization of existing teaching methods, instructional techniques and tools. Navigated by the fast-paced economy, employers outlined the competencies that would be essential for a new century generation. This created a challenge for universities to prepare young people for novelty and complexity in leading teambased projects, solving unexpected problems and making instant decisions. Project-based learning (PJBL) is supposed to manage these tasks by organizing the framework for student-centered and active learning approaches. 
Gradaleva \& Polukhina, 2020. Development of a Professional Training Course to Enhance PJBL Competencies of Teachers at a Technical University

In practice, many technical university educators do not feel prepared for implementing interdepartmental and cross-cultural projects as they feel the lack of a methodological base to integrate innovative techniques into their teaching. This is explained by the fact that the majority of them were certified through traditional technical education programs and traditional professional development courses.

Some educators are conservative. They will never accept anything new unless they see how well these approaches improve student achievement (Adey et al., 2004). They are always trying to find the reasons not to adopt changes. There is too much concern about making PJBL projects fit within the curriculum, meeting the expectations of administrators, aligning projects with final assessment criteria (Martinez, 2017).

PJBL exists at a technical university only in the form of course papers, graduate theses and conference reports. It becomes obvious that there is a need to rethink the design of teacher professional development. It is necessary to cultivate educators who will be able to demonstrate PJBL practices and be effective in preparing students for our increasingly project-based world. Thus, the research aim is to design a professional development course for technical university teachers where the special emphasis will be laid upon teacher preparation for cross-cultural project activities.

\section{Literature Review}

A project-based approach refers to teaching students how to plan and carry out a project that produces publicly-exhibited work such as a product, publication, or presentation (Patton, 2012). It is also defined as the synergy of instructional techniques which makes it possible to solve a problem due to self-directed learning resulting in the demonstration of the output (Polat et al., 2009).

Other features of PJBL involve authentic content, sustained inquiry, teacher facilitation but not direction, critique and revision, reflection, development of key $21^{\text {st }}$ century skills. They include setting goals, investigation, decision making, collaboration, creativity, innovation, global thinking, technology and communication (Thomas, 2000; Bell, 2010; Philen, 2016).

In our research, we follow the conception expressed by the majority of scholars. PJBL is a student-centered approach in which learners work in groups to solve an open-ended problem and present results. A teacher plays the role of a facilitator who encourages them to be independent to determine how and what they will learn in the course of the project. It is truly stated that teaching practices in PJBL should support students' self-regulated learning (English \& Kitsantas, 2013). The more control students take over their learning, the more motivated they become to complete the project and succeed (Clark, 2017). 
There are several reasons for launching a PJBL teacher preparation course at technical universities. Primarily, students need to be prepared for a project-based world. It means that teachers should be provided with professional development that will lead them to positive PJBL results (Liebtag \&Vander Ark, 2016). Teachers need to know how to coordinate project work of students, relate it to the real-world issues and their curriculum, help search resources, plan assessment throughout the project, and motivate students to cooperate effectively in groups (Railsback, 2002).

Many current methods are becoming out of date. University instruction is changing from traditional approaches to those based on active learning and the needs of students. They are associated with critical theory, case-study, problembased tasks, teamwork (Roessingh \& Chambers, 2011; Scherbakova, 2011). One project can cover all these issues provided that educators are properly trained to achieve that. Besides, PJBL implicates blended and personalized learning models, which also require new skills for teachers. It can be collaboration with colleagues regarding interdisciplinary projects as well as outlining a project that embodies standards and interests (Liebtag \&Vander Ark, 2016).

Internationalization fosters the implementation of international educational projects. The majority of them will be virtual. It means that in such context an additional set of competencies is required. M. Houston defines them as Transnational Communicative Competencies (TCCs): linguistic, rhetorical, cultural and spatial/media (Houston, 2017). They comprise some skills and strategies necessary for successful intercultural communication in online social spaces. Therefore, an existing teacher training program needs upgrading to support teachers working globally. This idea is also supported by the findings of J. Lopukhova and E. Makeeva describing new and valid methods to increase the effectiveness of university teacher professional development in the digitalized world (Lopukhova \& Makeeva, 2019).

The framework of teacher competencies should be a starting point around which to organize any professional training. It serves to understand the demands of new forms of pedagogy so that teachers can help students grow (Powell et al., 2014). Education focuses on having students develop the competencies within the standard. These outcomes are to be integrated into professional training objectives. It is not only important to share information with course listeners but to form competencies required for their teaching (Krasinskaya, 2011; Kopytova, 2012). That is why it is reasonable to use a competency-based approach while planning teacher preparation. This has led us to the development of PJBL teacher competencies pyramid, which will be discussed later on. 
Gradaleva \& Polukhina, 2020. Development of a Professional Training Course to Enhance PJBL Competencies of Teachers at a Technical University

\section{Methodology}

As a preliminary stage to developing a professional training course to enhance PJBL competences of teachers at a technical university, our task was to analyze teachers' voice with regard to PJBL. The questionnaire was designed for educators working at departments of humanities, social sciences and engineering of Samara State Technical University, who were requested to complete the online questionnaire via a survey platform called SurveyMonkey. Nine questions were formulated. They concern the familiarity with the PJBL concept, its types and phases, PJBL implementation experience in teaching practices, interdepartmental projects experience, opinions on the necessity of international project activities and desire to enhance the PJBL competencies by taking a professional training course. Except for two open-ended questions (qualitative research) where respondents were supposed to answer in open text format based on their knowledge, feeling, and understanding, all items were presented as closed structures multiple-choice test (quantitative research).

The questionnaire was created. Content validity, face validity, and internal reliability were assessed. A panel of experts on PJBL has been chosen to validate our questionnaire. It included the Head of the Linguistics and Intercultural Communication Department and experienced educators who successfully integrate PJBL into their teaching. The experts (n 5) completed detailed content validity assessments with high scores for importance and appropriateness, although some paraphrasing of questions was required. According to face validity testing, the questionnaire didn't take long to complete (5-10 min) and was comprehensible. To assess the internal reliability of multiple-choice questions, we obtained Cronbach's alpha scores ranged from 0.73 to 0.89 , showing good internal consistency.

As soon as the questionnaire was finally ready, we identified sixty-three educators as participants of the study.

\section{Research Results}

The questionnaire inquired about teachers' perceptions of PJBL at Samara State Technical University. All 63 respondents are familiar with the concept of Project-Based Learning. However, only 33\% of teachers know the methodology details, $54 \%$ are partly aware and $13 \%$ answered in the negative. But what was interesting is that even most of them don't have a holistic view of the PJBL features, 92\% replied that they have experience in implementing PJBL in their teaching practices. The respondents wrote 58 comments providing examples of activities they apply within their course. There were such PJBL activities as course papers, conference reports and graduate theses. At the same time, teachers 
provided the reasons for what prevents them from implementing Project-Based Learning into their course on a constant basis. The most prevalent comments were time restrictions, fitting them within the curriculum, a low level of motivation, lack of knowledge in this field and problems with control and assessment. $43 \%$ of educators had experience in facilitating interdepartmental projects. As for the significance of international project activities, all teachers replied in the positive, but only $26 \%$ had experience in carrying them out with their students.

Results from the research questionnaire concluded that despite the constraints and the lack of a methodological base, most teachers support the implementation of PJBL in their teaching context. It is based on the answers of $94 \%$ of respondents, who have expressed interest in taking a professional training course. Hence, this course is in demand to enhance the PJBL competencies with an emphasis on teacher preparation for international project activities.

To better understand the ways of orienting teachers toward the project-based approach, we have worked out the Pyramid of PJBL Teacher Development. It presents teacher competencies and qualities necessary for facilitating educational projects and helps choose the best instructional methods and tools to develop them. Thus, the pyramid will serve as the basis for the professional training course content.

\section{The Framework of PJBL Teacher Competencies and Qualities}

The Pyramid of PJBL Teacher Development (Fig. 1) consists of five layers. It shows the competencies and qualities to be mastered during a PJBL professional training course.

Motivation is the basic element of the framework. A motivated teacher will take every opportunity to make innovative changes in the classroom required for new social demands. PJBL will have a better chance to bring about the desired benefits for students if teachers have a strong motivation to experiment with and improve it in their course (Lam et al., 2010). There are extrinsic and intrinsic motivations that can be encouraged. Extrinsic motivation is driven by external rewards such as money or praise. This type of motivation arises from outside the individual (i.e. external obligation), whereas intrinsic motivation originates inside of the individual (i.e. internal desires). Intrinsic motivation involves engaging in a behavior because it is personally rewarding; essentially, performing an activity for its own sake rather than the desire for some external rewards (Lee et al., 2012). An external obligation can be internalized, hence leading to teacher's autonomy in implementing PJBL. However, extrinsic motivation still has a lower degree of autonomy than intrinsic motivation.

According to the integrated model of teacher motivation (Jesus \& Lens, 2005), teachers have high motivation if they have a high expectancy of success. 
Gradaleva \& Polukhina, 2020. Development of a Professional Training Course to Enhance PJBL Competencies of Teachers at a Technical University

If teachers feel pressure from above (administration constraints), their teaching becomes less intrinsically motivated. Thus, teachers will have more enthusiasm to launch new projects if they feel the support of the administration. It is important to give them the time and resources to make their ideas real.

The second layer of the pyramid encompasses personal qualities helping an educator make the transition to new methods of teaching. These are flexibility, orientation towards innovation and lifelong learning. Such models of behavior can be understood and adopted. They lead to the shift from teacher-led instruction to student-centered learning, creation of personalized learning environments that are dependent on authentic content and sustained inquiry, promotion of independent and self-directed learning, initiation of change according to students' needs and progress. Flexible teachers oriented towards innovation are able to embrace uncertainty and show readiness to deal with irregularities.

Lifelong learning mindset means an interest in development at various conferences, round-table sessions, and teacher preparation courses. At the same time, doing projects with students by itself can be considered as job-embedded professional training. Projects are new learning opportunities not only for students but for teachers as well. Educators are effective if they are curious about the project outcome and are eager to learn new things from it. Their enthusiasm will play a decisive role when students face difficulties and dead-end. If a teacher is indifferent to results, the students will be unmotivated too.

The third layer of the pyramid shows the necessity of understanding PJBL methodology (know-how). According to our survey, the majority of educators pointed out the importance of acquiring this particular knowledge base. It can be done through instruction and training. Teachers will be prepared to determine the benefits of a specific project for students' learning, analyze the tasks required for project implementation, help students set goals, plan an investigation and evaluate results, facilitate the growth of interpersonal traits and competencies.

PJBL is not a process pre-planned in every detail, which means that a teacher should be skilled to tackle unexpected problems, communicate effectively while managing a student project, apply critical-thinking and creativity in dealing with project tasks. That is why the fourth layer of the pyramid presents XXI century competencies: critical-thinking, creativity, collaboration, communication, problem-solving, and decision making. They can be developed through coaching and modeling. Teachers should be engaged in project-based experiences themselves. Doing project tasks within the scope of professional training will allow them to feel what it is like to learn through projects. Consequently, it will make them better facilitators.

This four-layer pyramid can be defined as self-sufficient if we consider PJBL teacher development at the national level. International project implementation requires the formation of competencies following four trajectories of transnational 
communication: linguistic, cultural, rhetorical and media. As we have already mentioned, M. Houston calls them Transnational Communicative Competencies. They form the topmost layer of the pyramid.

Information and communication technologies make it easier for teachers around the world to do joint educational projects. Now students can carry out research with their peers from other countries, search and share bibliography, exchange views and present results. In this context, teachers need to know a foreign language well enough for working at the global level (linguistic trajectory), apply appropriate strategies to achieve communicative success (rhetorical trajectory), understand people with different cultural backgrounds (cultural trajectory), and perform well in the digital space (media trajectory).

Professional development course will bring together communication, intercultural and IT aspects to be used by teachers in their transnational project activities. They will be mastered through instruction, training and practice.

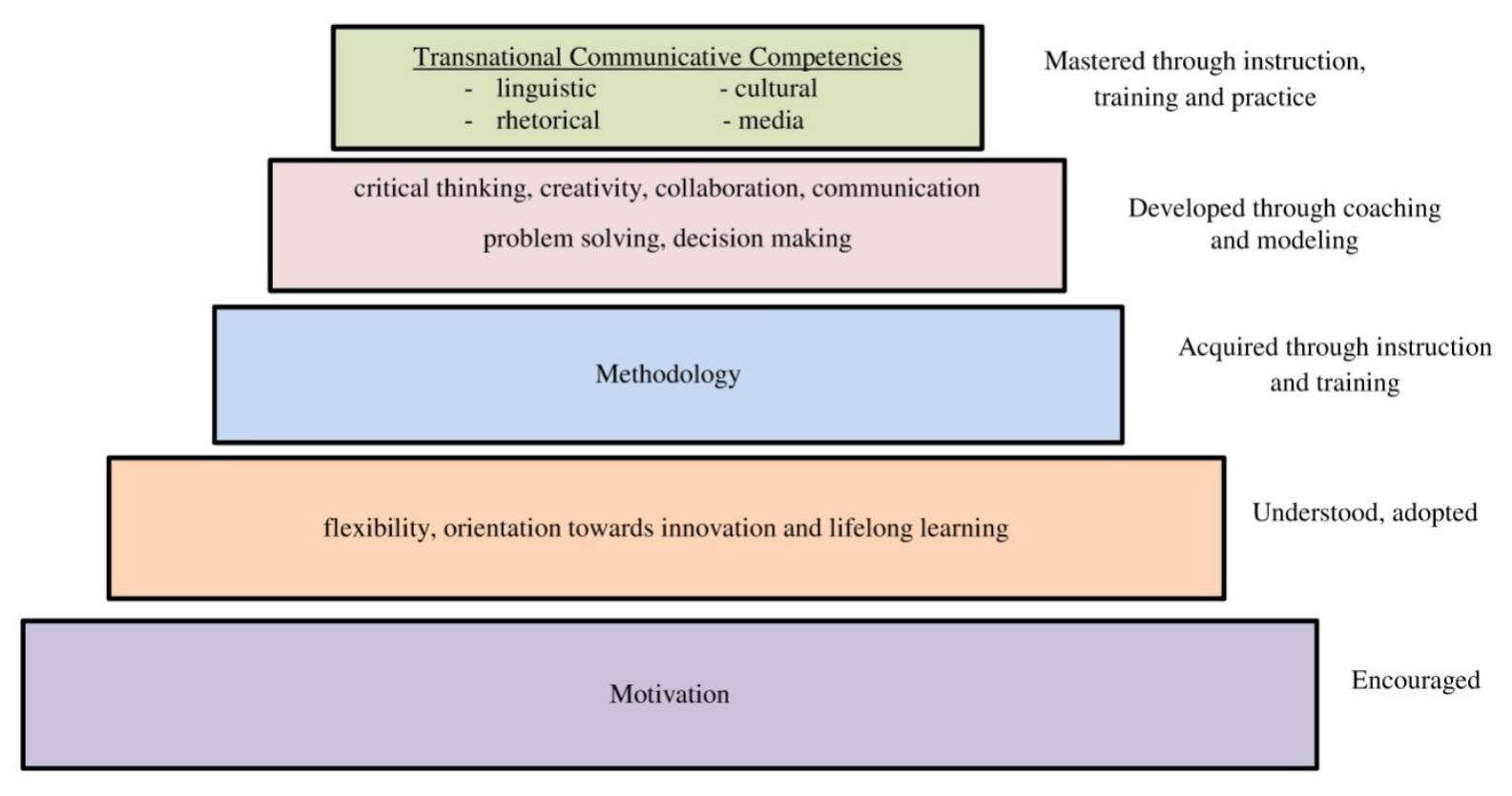

Figure 1 The Pyramid of PJBL Teacher Development

\section{Professional Development Course Content}

Professional training for technical university teachers is designed as a 72hour course. It embraces the main principles which a teacher should ideally know to be effective in applying a project-based approach. Also, it aims at preparation for international project implementation; therefore, much attention is paid to transnational communicative competencies development. 
Gradaleva \& Polukhina, 2020. Development of a Professional Training Course to Enhance PJBL Competencies of Teachers at a Technical University

The program contains four modules: PJBL Methodology (36 academic hours); Professional English and Intercultural Communication (20 academic hours); Information and Communication Technologies (8 academic hours); Workshop of a visiting Professor (8 academic hours). It combines competencybased, personalized and need-focused learning. Besides, it is planned as a projectbased course providing teachers with an opportunity to do meaningful pedagogical projects. This will help cultivate XXI century competencies presented in the fourth layer of the PJBL Teacher Development Pyramid. The workshop will work as a demonstration of mastery and a motivating factor to PJBL proliferation at the University.

PJBL Methodology covers such issues as benefits of project-based instruction, components of an educational project, essentials for planning projects (getting ideas, setting goals, working out the timeline, filling out a project schedule), and the role of a teacher in a PJBL classroom, potential difficulties, assessment, instructional critique and peer critique, cross curriculum project implementation, the scheme of transnational project work.

A problem-based approach will be used to generate self-directed learning. During PJBL Methodology sessions teachers will be proposed to think over some challenging open-ended questions. The following can serve as examples:

1. Project-based learning: teacher enthusiasm or resistance?

2. Traditional teacher-led instruction or project-based learning?

3. The warranty for success with your project. Does it exist?

4. Projects and difficulties. Can you finish the project midway if it is going badly?

5. Assessment isn't just about the final output. Is it true?

At the end of a PJBL Methodology module teachers will present project drafts created for their disciplines. Special emphasis will be laid upon the summary of project ideas, a list of things they are excited about and things they are worried about. The following prompts are proposed as examples to initiate discussion: A) Does this project fulfill PJBL design principles well? B) How could I make the project more authentic? C) What is the best format for presenting the final results? D) Can we think of other teachers, friends, organizations that might get involved in this project? What roles could they play?

The curriculum of teacher professional training is strongly connected with transnational communicative competencies, which form the top of the PJBL Teacher Development Pyramid. The course of Professional English and Intercultural Communication deals with linguistic, rhetorical and cultural trajectories, while the course of ICT is focused on developing media skills.

In 2017 we designed and carried out the International Conference Project (ICP) in collaboration with Notre Dame College (U.S.). It was a virtual initiative aimed at developing students' intercultural communication skills by means of 
joint research. The difficulties our students faced helped identify the set of competencies necessary for effective transnational cooperation. Accordingly, it was possible to specify what kind of knowledge and skills an educator needs to facilitate the work on the international project. And this forms the base of our professional training course.

The module of Professional English and Intercultural Communication will teach how to motivate students to communicate with foreign partners, respect other cultures, accept a different type of mindset, be able to express their point of view successfully and achieve consent. More attention will be paid to rhetoric rather than to grammar or lexis.

ICP testifies that a small amount of grammar and lexical mistakes Russian students made did not obscure discussion. However, U.S. students felt uncomfortable when slang was used in conversation. Also, Russian students often finished their responses with a statement, which caused confusion. It was not clear for Americans how to continue the dialogue. Teachers trained students to apply several communicative strategies to show interest in conversation and sound more polite.

Furthermore, rhetorical issues can cause a decrease in motivation. In the middle phase of ICP Russian students admitted that they were not content with "the short answers of their U.S. peers". It was significant for facilitators to explain the specifics of a professional genre to encourage participants. American students strictly followed an academic writing style, which is characterized by clear, focused and concise utterances on the topic. In Russia long responses indicate interest, but not in the U.S. It was necessary to help Russian students understand that Americans do want to work with them. At the same time, U.S. teachers had to involve their groups in using different strategies to engage.

Indeed, ICP reveals the necessity to prepare teachers for dealing with rhetorical, linguistic, cultural and media issues. It becomes obvious that they should be skilled to sharpen transnational communicative competencies of students and help them overcome the difficulties that may occur in our global world.

\section{Discussion and Conclusions}

The poll has shown that only about a third of teachers know the details of PJBL methodology, even though the majority uses it in the classroom. These results are similar to the findings of V.A. Kapranova and I.M. Shvetz, who state that many educators know how to plan a project and fulfill its main phases but are not aware of the whole PJBL methodology, including project management (Kapranova, 2014; Shvetz, 2014). According to the survey by E. Liebtag and 
Gradaleva \& Polukhina, 2020. Development of a Professional Training Course to Enhance PJBL Competencies of Teachers at a Technical University

T. Vander Ark, practicing teachers admit they do not feel prepared for PJBL and that their professional learning doesn't help. (Liebtag \& Vander Ark, 2016).

Educators have expressed much concern about making PJBL projects fit within the curriculum, meeting time restrictions, lack of knowledge in a specific field, problems with control and assessment. The same doubts were observed by J.E. Martinez during professional development sessions in PJBL implemented by the Buck Institute (Martinez, 2017). The issues of assessment are also discussed in the works by B.A. Clark and J. Railsback (Clark, 2017; Railsback, 2002). A considerable amount of our respondents mentioned a low level of motivation to finish projects, which is not aligned with the investigations of J.W. Thomas and A. Kavlu showing the improved attitude of students towards learning (Thomas, 2000; Kavlu, 2017).

The results of our findings reveal that almost all teachers support the idea of PJBL implementation and are interested in taking a professional training course. The statistics support the observations of J. Strobel and A. van Barneveld who noticed that teachers usually find PJBL more rewarding and enjoyable than traditional approaches (Strobel \& van Barneveld, 2009).

Based on the results of the questionnaire, we have justified the necessity of developing a professional training course for technical university teachers in the field of PJBL with an emphasis on international project activities. The next stage to orient teachers toward the project based approach was to create the Pyramid of PJBL Teacher Development, which will provide teachers with necessary competencies and qualities. Thus, we have presented the five-layer Pyramid, where motivation is the first layer. The second layer includes flexibility, orientation towards innovation and lifelong learning. The third layer is the methodological base (know-how). The fourth layer of the pyramid presents XXI century competencies: critical-thinking, creativity, collaboration, communication, problem-solving, and decision making. As we are also focusing on international activities in our research, the fifth layer consists of Transnational Communicative Competencies, i.e. linguistic, cultural, rhetorical and media.

As a result, we have created a professional development course for university teachers aiming at international projects. The 72-hour course contains four units: PJBL Methodology; Professional English and Intercultural Communication; Information and Communication Technologies; Workshop of a visiting Professor. The workshop is thought to work as a motivating factor and a trigger to PJBL proliferation at the University.

Overall, our results provide the option of immediate application as we have suggested the structure of the holistic approach to enhance PJBL competencies of teachers at the technical university. A further option for future research would be to analyze teacher's perceptions after the course. 
SOCIETY. INTEGRATION. EDUCATION

Proceedings of the International Scientific Conference. Volume I, May $22^{\text {th }}-23^{\text {th }}, 2020.169-180$

\section{References}

Adey, P., Hewitt, G., Hewitt, J., \& Landau, N. (2004). The professional development of teachers: Practice and theory. Dordrecht: Kluwer Academic.

Bell, S. (2010). Project-Based Learning for the 21st Century: Skills for the Future. The Clearing House: A Journal of Educational Strategies, Issues and Ideas, 83(2), 39-43.

Clark, B.A. (2017). Project-based Learning: Assessing and Measuring Student Participation. Research and Evaluation in Literacy and Technology, 39. Retrieved from https://digitalcommons.unl.edu/cgi/viewcontent.cgi?article=1041\&context=cehsgpirw.

English, M.C., \& Kitsantas, A. (2013). Supporting Student Self-Regulated Learning in Problem- and Project-Based Learning. Interdisciplinary Journal of Problem-Based Learning, 7(2), 127-150.

Houston, M. (2017). Re-Imagining Linguistic Competence and Teaching Towards Communicative Success in Transnational and Translingual Spaces of Today's Global Reality. Crosspol Journal, 3(1), 18-35.

Jesus, S.N., \& Lens, W. (2005). An integrated model for the study of teacher motivation. Applied Psychology: An International Review, 54, 119-134.

Kapranova, V.A. (2014). Project-based Learning at Universities: Historical and Technological Aspects. Izvestia VGPU, 3(264), 78-80.

Kavlu, A. (2017). Implementation of Project Based Learning (PJBL) in EFL (English as a Foreign Language) Classrooms in Fezalar Educational Institutions (Iraq). International Journal of Social Sciences \& Educational Studies, 4(2), 67-79.

Kopytova, N.E. (2012). Teacher Professional Development: Current Standing and Problems. Vestnik TGU - Bulletin of Tambov University, 4(108), 108-117.

Krasinskaya, L.F. (2011). Teacher Professional Development: a Model of Implementing a Competency-based Approach. Vysshee Obrazovanie v Rossii - Higher Education in Russia, 7, 75-80.

Lam, S.F., Cheng, R.W.Y., \& Choy, H. C. (2010). School support and teacher motivation to implement project-based learning. Learning and Instruction, 20(6), 487-497.

Lee, W., Reeve, J., Xue, Y., \& Xiong, J. (2012). Neural Differences between Intrinsic Reasons for Doing Versus Extrinsic Reasons for Doing: an FMRI Study. Neurosci Res, 73(1),

68-72. doi:10.1016/j.neures. 2012.02.010

Liebtag, E., \& Vander Ark, T. (2016). Preparing Teachers for a Project-based World. US: Getting Smart.

Lopukhova, J., \& Makeeva, E. (2019). University Teacher Professional Development in the Digital World. Advances in Intelligent Systems and Computing, 917, 514-524.

Martinez, J.E. (2017). The Search for Method in STEAM Education. Palgrave Studies in Play, Performance, Learning, and Development, 21-33.

Patton, A. (2012). Work that Matters: the Teacher's Guide to Project-based Learning. London: Paul Hamlyn Foundation.

Philen, J. (2016). Implementing Meaningful And Sustainable Project Based Learning Pedagogy (Doctoral Dissertation). All Theses and Dissertations. 103. Retrieved from https://dune.une.edu/theses/103/

Polat, E.S., Bukharkina, M.Yu., Moiseeva, M.V., \& Petrov, A.E. (2009). New Pedagogical and Information Technologies in Education. Moscow: Akademia.

Powell, A., Rabbitt, B., \& Kennedy, K. (2014). iNACOL Blended Learning Teacher Competency Framework. Vienna. VA: iNACOL. 
Gradaleva \& Polukhina, 2020. Development of a Professional Training Course to Enhance PJBL Competencies of Teachers at a Technical University

Railsback, J. (2002). Project-based Instruction: Creating Excitement for Learning.US: Northwest Regional Educational Laboratory.

Roessingh, H., \& Chambers, W. (2011). Project-Based Learning and Pedagogy in Teacher Preparation. International Journal of Teaching and Learning in Higher Education, 23(1), 60-71.

Scherbakova, I.A. (2011). The Project Method in Teaching English: Interrelation of Learning and Practice. Kazanskiy pedagogocheskiy zhurnal-Kazan Pedagogical Journal, 5-6(89-90), 33-40.

Shvetz, I.M. (2014). Project Method. Peculiarities and Problems of Implementation at Universities. Vestnik of Lobachevsky State University of Nizhni Novgorod, 3(4), 235-240.

Strobel, J., \& van Barneveld, A. (2009). When Is PJBL More Effective? A Meta-Synthesis of Meta-Analyses Comparing PJBL to Conventional Classrooms. The Interdisciplinary Journal of Problem-Based Learning, 3(1), 43-58.

Thomas, J.W. (2000). A Review of Research on Project-based Learning. Novato, CA: Buck Institute for Education. 